\title{
BMJ Open Association between birth weight and neurodevelopment at age 1-6 months: results from the Wuhan Healthy Baby Cohort
}

\author{
Man Zhang (D) , ${ }^{1}$ Marufu Martin Gazimbi, ${ }^{2}$ Zhong Chen, ${ }^{3}$ Bin Zhang, ${ }^{3}$ Yanru Chen, ${ }^{1}$ \\ Yizhen Yu, ${ }^{4}$ Jie Tang ${ }^{1}$
}

To cite: Zhang M, Gazimbi MM, Chen Z, et al. Association between birth weight and neurodevelopment at age 1-6 months: results from the Wuhan Healthy Baby Cohort. BMJ Open 2020;10:e031916. doi:10.1136/ bmjopen-2019-031916

- Prepublication history and additional material for this paper are available online. To view these files, please visit the journal online (http://dx.doi. org/10.1136/bmjopen-2019031916).

Received 19 June 2019 Revised 30 October 2019 Accepted 10 December 2019

Check for updates

(c) Author(s) (or their employer(s)) 2020. Re-use permitted under CC BY-NC. No commercial re-use. See rights and permissions. Published by BMJ.

${ }^{1}$ Department of Preventive Medicine, School of Public Health, Guangzhou Medical University, Guangzhou, Guangdong, China

${ }^{2}$ Global Development Institute, The University of Manchester, Manchester, UK

${ }^{3}$ Department of Child Health Care, Wuhan Medical and Healthcare Center for Women and Children, Wuhan, China

${ }^{4}$ Child and Women Health Care, School of Public Health, Tongji Medical College, Huazhong University of Science and Technology, Wuhan, Hubei, China

Correspondence to

Professor Jie Tang;

james.tang@wlv.ac.uk

\section{ABSTRACT}

Objective The association between birth weight and infants' neurodevelopment is not well understood. We aimed to examine the impact of birth weight on neurodevelopment of infants at age 1-6 months using data from the Wuhan Healthy Baby Cohort (WHBC) study. Setting and participants This is a prospective cohort study of 4026 infants from the WHBC study who were born at the Women and Children's Hospital of Wuhan, China between October 2012 and September 2013 and who had complete healthcare records within 6 months after birth. Participants were categorised into three groups according to their birth weight: low birth weight (LBW; birth weight $<2500 \mathrm{~g}$ ), normal birth weight $(2500 \mathrm{~g} \leq$ birth weight $<4000 \mathrm{~g}$ ) and macrosomia (birth weight $\geq 4000 \mathrm{~g}$ ).

Main outcome measures The main outcomes were development quotient (DQ) and clinical diagnosis of neurodevelopmental delay. Both adjusted regression coefficients and ORs were estimated for LBW and macrosomia.

Results Of the 4026 infants, 166 (4.12\%) were of LBW and 237 (5.89\%) were with macrosomia. Adjusted regression coefficients of $L B W$ and macrosomia for gross motor DQ were $-11.18(95 \% \mathrm{Cl}-11.36$ to 10.99$)$ and 0.49 (95\% $\mathrm{Cl} 0.36$ to 0.63$)$, fine motor DQ -6.57 (95\% $\mathrm{Cl}-6.76$ to -6.39$)$ and $-2.73(95 \% \mathrm{Cl}-2.87$ to -2.59$)$, adaptability DQ $-4.87(95 \% \mathrm{Cl}-5.05$ to -4.68$)$ and -1.19 $(95 \% \mathrm{Cl}-1.33$ to -1.05$)$, language $\mathrm{DQ}-6.23(95 \% \mathrm{Cl}$ -6.42 to -6.05$)$ and $0.43(95 \% \mathrm{Cl} 0.29$ to 0.57$)$, and social behaviour $\mathrm{DQ}-6.82(95 \% \mathrm{Cl}-7.01$ to -6.64$)$ and $1.10(95 \% \mathrm{Cl} 0.96$ to 1.24). Adjusted OR of LBW for clinical diagnosis of 'neurodevelopmental delay' in gross motor was 2.43 (95\% Cl 1.65 to 3.60), fine motor $1.49(95 \% \mathrm{Cl}$ 1.01 to 2.19 ) and adaptability 1.56 ( $95 \% \mathrm{Cl} 1.06$ to 2.31 ). LBW has no significant effects on 'neurodevelopmental delay' in language and social behaviour, and macrosomia has no significant effects on clinical diagnosis of 'neurodevelopmental delay' in all domains.

Conclusion Both LBW and macrosomia are associated with infants' $D Q$, and LBW increases the risk of being diagnosed with 'neurodevelopmental delay' in gross motor, fine motor and adaptability among infants aged 1-6 months.
Strengths and limitations of this study

- The study used a prospective cohort design to investigate the association of birth weight with neurodevelopment in infants aged 1-6 months in China.

- Potential confounders including the method of delivery, number of prenatal visits, maternal active or passive smoking, gestational age, gender, birth length, asphyxia neonatorum, and prenatal sociodemographic information were adjusted.

- The study did not have data on infants' neurodevelopment after 6 months of age, which were required to further demonstrate the effects of birth weight on long-term neurodevelopment.

- There are only few neurodevelopmental assessment items for infants aged 1-6 months in the revised Gesell Development Scale (GDS), leading to less sensitive assessment results, and GDS is not commonly used in Western countries, making it difficult to compare the results with studies from Western countries.

\section{INTRODUCTION}

Birth weight (BW) is a strong indicator of maternal and newborn health and nutrition. Low birth weight (LBW) increases the risk of death in the early months and years of a child's life, and those who survive tend to have impaired immune function and increased risk of infectious diseases. They are also likely to remain undernourished, with reduced muscle strength, cognitive abilities and IQ throughout their lives. ${ }^{12}$ It is estimated that more than 22 million infants are of LBW annually, and majority of them are in low-income and middle-income countries, ${ }^{3}$ accounting for $60 \%-80 \%$ of all neonatal deaths worldwide. ${ }^{4}$ In China, it is reported that the rate of LBW was significantly reduced from $4.4 \%$ in 2006 to $2.4 \%$ in $2012 .{ }^{5}$ Despite remarkable achievement made in combating LBW, enormous challenges remain. Evident in national figures are numerous disparities 
within the country, with high rates of LBW being reported in undeveloped and remote areas. ${ }^{6}$ With the survival rate of LBW infants greatly improved due to advancements in medical technology and neonatal care, new problems such as growth delay and neurodevelopmental disorders in infants are emerging. ${ }^{7}$

As BW is an important indicator of health status of a fetus, it has profound impact on a child's health and development. It is believed that BW reflects the intrauterine nutritional status of the fetus, which usually affects physical development, including neurodevelopment within 3 years. ${ }^{8}$ The impact of BW can be intensified through acquired environmental factors that facilitate the development of diseases later in life. Recent studies have shown that the association between birth order, which is a proxy for pathogen exposure, and childhood leukaemia may be changed by BW, making children more susceptible to leukaemia. ${ }^{9}$ Additionally, BW has been reported to have an association with increased risk of chronic disease development, such as type 2 diabetes, abdominal obesity and hypertension. ${ }^{10}$ Studies have also shown that LBW infants' physical and neurobehavioural development lags behind infants with normal birth weight (NBW) within 12 months, ${ }^{11}{ }^{12}$ and LBW infants have increased risk of attention deficit hyperactivity disorder, cerebral palsy, visual impairment and deafness. ${ }^{13} 14$

Although there is evidence that LBW is a risk factor for neurodevelopmental delay, few studies have been conducted to confirm this association in developing and undeveloped countries such as in China, ${ }^{7}$ where majority of newborns of LBW are born. The available evidence from high-income countries cannot be generalised across the world because neurodevelopment can be influenced by many factors such as socioeconomic and culture factors, which greatly vary between developing and developed countries. ${ }^{15}$ China is the largest developing country in the world and is the first country to implement onechild policy nearly 40 years ago. ${ }^{16}$ Fewer studies have investigated the impact of BW on neurodevelopment and at the early stage of infancy, which is the best time to identify at-risk babies and to intervene, although the policies and interventions have been progressive in achieving positive maternal and child healthcare outcomes. ${ }^{17}$ In this study, we used a prospective cohort design to assess the impact of BW on neurodevelopment in infants at age $1-6$ months.

\section{MATERIALS AND METHODS \\ Data sources}

Data for this study were extracted from the Wuhan Healthy Baby Cohort (WHBC), specifically designed to investigate factors associated with child growth and development. The detailed proposal of this cohort has been described previously. ${ }^{18}$ In the present study, we included a subgroup of infants who were born at the Women and Children's Hospital of Wuhan, China between October 2012 and September 2013 and who have complete healthcare records within 6 months after birth. Data on antenatal, labour and postnatal care were extracted from their mothers' healthcare records. The unambiguous linkage of healthcare records of infants and their mothers was feasible due to the unique identifier assigned at birth and which is used in the medical information system of the hospitals. Participants were excluded if over $15 \%$ of information on their records was missing. Participants who had birth defects, who had been admitted to neonatal intensive care unit and who had neonatal sepsis were also excluded. We finally incorporated 4026 infants after excluding 24 infants with birth defects and 116 participants with incomplete medical records.

\section{BW measurement and classification}

BW is defined as the first weight taken within 1 hour of birth, measured by obstetricians or midwives using a baby scale (accuracy $10 \mathrm{~g}$ ) while the baby's body remained dry and unwrapped. In this study, BW was categorised into LBW (BW <2500 g), NBW $(2500 \mathrm{~g} \leq \mathrm{BW}<4000 \mathrm{~g})$ and macrosomia (BW $\geq 4000 \mathrm{~g}$ ) according to the diagnostic criteria of the American College of Obstetricians and Gynecologists. ${ }^{19}$ BW categories in the medical information system of Women and Children's Medical and Healthcare Center of Wuhan were coded using the International Classification of Diseases, Tenth Revision. We ascertained the following diagnosis: LBW (code P07.151) and macrosomia (code O33.501).

\section{Neurodevelopmental assessment}

The Gesell Development Scale (GDS), developed by Gesell and Amatruda, ${ }^{20}$ is a useful tool to determine the integrity and maturity of the nervous system in children. The Chinese version of GDS was revised by the Chinese Pediatric Association in 1986 and has been shown to have strong internal reliability and validity. ${ }^{21}$ It has been widely used to evaluate the function of the nervous system ${ }^{22}$ and to identify whether the nerve muscle or sensory system is defective. ${ }^{23}$ It is also used to clinically diagnose developmental delay in infants and children. ${ }^{24}$ The items of the Chinese version of GDS are grouped into five neurodevelopmental domains: gross motor, fine motor, adaptability, language and social behaviour. Specifically, gross motor includes raising the head, standing and working; fine motor includes hand control and balance; adaptability includes imitation, discriminative performance and perception; language was assessed by means of vocabulary, word comprehension and conversation; and social behaviour includes reactions to persons, personal habits and acquired information.

All of the neurodevelopmental tests were assessed at the Developmental Neuropsychology Laboratory and at age 1-6 months by four trained paediatricians, who were 'blind' to the prenatal and perinatal background of the infants. Maturity age can be used to calculate a development quotient $(\mathrm{DQ})$, which is the maturity age divided by the chronological age, multiplied by $100 .{ }^{25} \mathrm{DQ}$ is corrected if the infant is preterm. Higher DQ is always associated 
with better neurodevelopment. According to the Chinese norm, the $\mathrm{DQ}$ scores for the total and the five clinical domains were classified into 'low $(\mathrm{DQ}<70)$ ', 'middle and lower $(70 \leq \mathrm{DQ} \leq 84)$ ', 'medium $(85 \leq \mathrm{DQ} \leq 114)$ ', 'middle and upper $(115 \leq \mathrm{DQ} \leq 129)$ ' or 'high $(\mathrm{DQ} \geq 130)$ ' level. Neurodevelopmental delay can be diagnosed when the infant's neurodevelopmental status was rated as 'middle and lower' and 'low'; relevant clinical intervention should also be performed. ${ }^{26}$

\section{Covariables}

Covariables included the method of delivery (natural or caesarean delivery), number of prenatal visits, maternal active or passive smoking (yes or no), gestational age (continuous data), gender (boy or girl), birth length (continuous data), asphyxia neonatorum (yes or no), and prenatal sociodemographic information such as maternal and paternal education.

\section{Statistical analysis}

Mean and SD or frequencies and percentages were used to describe the characteristics of the study participants. We calculated DQ and made a neurodevelopmental diagnosis of the five domains for each infant, both of which were examined as the outcomes. Two methods were used to examine the association between DQ and infants' BW: first, we used one-way analysis of variance (ANOVA) to compare the mean of DQ among different BW categories, and then the prediction of BW was examined with adjustment for other covariables in generalised linear model (GLM) with DQ as the outcome.

Also, the association between BW and the diagnosis of neurodevelopmental domains was examined in two ways. First, $\chi^{2}$ test was used to analyse the incidence of neurodevelopmental delay among different categories of BW. Second, we used BW as the independent variable and neurodevelopmental diagnosis as the dependent variable, and entered the control variables into the binary logistic regression models, and estimated the OR to predict the neurodevelopmental diagnosis.

In both GLM and logistic regression analyses, we adjusted for prenatal factors (maternal active and passive smoking, and number of pregnancy tests), perinatal factors (gender of infants, delivery mode, asphyxia neonatorum and birth length) and maternal demographic factors (gestational weeks and education level of parents) that may be potential confounders of the association of BW with neurodevelopment. All statistical analyses were conducted using SPSS V.15.0. Statistical significance was defined as a $\mathrm{p}$ value less than 0.05 , and all tests were two-sided.

\section{Patient and public involvement}

This study was done without patient involvement. Patients were not invited to comment on the study proposal and were not consulted to develop patient relevant outcomes or to interpret the results. Patients were not invited to contribute to the writing and editing of this document for readability or accuracy.

\section{RESULTS}

\section{Overview}

The sociodemographic and clinical characteristics of the participants are shown in table 1. Of the 4026 infants, $55.8 \%$ were boys. The mean gestational age was $38.8 \pm 1.3$ weeks, with a mean BW of $3300.7 \pm 4.6 \mathrm{~g}$ and a mean birth length of $50.1 \pm 1.8 \mathrm{~cm}$. Of the infants, $0.2 \%$ (7 of 4026 ) had neonatal asphyxia, $5.9 \%$ (237 of 4026) had macrosomia and 4.1\% (166 of 4026) had LBW. Significant associations between BW and gender, birth length, gestational age, mode of delivery and number of prenatal tests were found. The median time of neurodevelopment assessment was 3.7 (IQR: 2.5-4.1) months.

\section{Association of BW with DQ}

Table 2 shows the associations between BW and DQ in different domains of neurodevelopment. One-way ANOVA found BW was significantly associated with DQ in gross motor $(F=62.082, \mathrm{p}<0.001)$, fine motor $(F=41.797$, $\mathrm{p}<0.001)$, adaptability $(F=13.839, \mathrm{p}<0.001)$, language $(F=14.206, \mathrm{p}<0.001)$ and social behaviour $(F=19.279$, $\mathrm{p}<0.001)$. The DQ between the different BW groups in different neurological domains was further compared, and the results are shown in online supplementary appendix 1. DQ in all neurological domains of LBW infants is significantly lower than NBW and macrosomia infants, while there was no significance between NBW and macrosomia infants in all neurological domains. GLM analysis (see online supplementary appendix 2) demonstrated a negative linear relationship between LBW and $\mathrm{DQ}$ in gross motor $(\mathrm{B}=-11.18,95 \% \mathrm{CI}-11.36$ to -10.99$)$, fine motor $(\mathrm{B}=-6.57,95 \% \mathrm{CI}-6.76$ to -6.39$)$, adaptability $(\mathrm{B}=-4.87,95 \% \mathrm{CI}-5.05$ to -4.68$)$, language $(\mathrm{B}=-6.23,95 \% \mathrm{CI}-6.42$ to -6.05$)$ and social behaviour $(\mathrm{B}=-6.82,95 \% \mathrm{CI}-7.01$ to -6.64$)$. There was negative linear relationship between macrosomia and $\mathrm{DQ}$ in fine motor $(\mathrm{B}=-2.73,95 \% \mathrm{CI}-2.87$ to -2.59$)$ and adaptability $(\mathrm{B}=-1.19,95 \%$ CI -1.13 to -1.05$)$, and positive linear relationship between macrosomia and $\mathrm{DQ}$ in gross motor $(\mathrm{B}=0.49,95 \%$ CI 0.36 to 0.63$)$, language $(\mathrm{B}=0.43,95 \%$ CI 0.29 to 0.57$)$ and social behaviour $(\mathrm{B}=1.10,95 \%$ CI 0.96 to 1.24$)$.

\section{Association of BW with neurodevelopmental diagnosis}

Table 3 shows the neurodevelopmental delay in five domains and its association with BW. Significantly, $\chi^{2}$ tests found BW was associated with neurodevelopmental delay in gross motor $\left(\chi^{2}=107.255, \mathrm{p}<0.001\right)$, fine motor $\left(\chi^{2}=70.295, \mathrm{p}<0.001\right)$ and adaptability $\left(\chi^{2}=9.073\right.$, $\mathrm{p}=0.011$ ). Binary logistic regression model (see online supplementary appendix 3) indicated LBW was a risk factor of infants' neurodevelopmental delay in gross motor (adjusted OR $(\mathrm{aOR})=2.43, \quad 95 \% \mathrm{CI} \quad 1.65$ to 3.60 ), fine motor (aOR $1.49,95 \%$ CI 1.01 to 2.19 ) and 
Table 1 Demographic characteristics of participants

\begin{tabular}{|c|c|c|c|c|}
\hline & \multicolumn{3}{|c|}{ Birth weight } & \multirow[b]{3}{*}{ Total $(\mathrm{N}=4026)$} \\
\hline & LBW & NBW & Macrosomia & \\
\hline & $(n=166)$ & $(n=3623)$ & $(n=237)$ & \\
\hline \multicolumn{5}{|l|}{ Parental demographic factors } \\
\hline 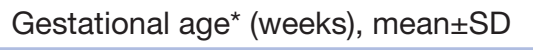 & $36.1 \pm 2.2$ & $38.9 \pm 1.2$ & $39.4 \pm 0.9$ & $38.8 \pm 1.3$ \\
\hline \multicolumn{5}{|l|}{ Mothers' education, $\mathrm{n}(\%)$} \\
\hline Bachelor or above & $51(30.7)$ & $1333(36.8)$ & $84(35.4)$ & $1468(36.5)$ \\
\hline Below bachelor & $115(69.3)$ & $2290(63.2)$ & $153(64.6)$ & $2558(63.5)$ \\
\hline \multicolumn{5}{|l|}{ Fathers' education, n (\%) } \\
\hline Bachelor or above & $53(31.9)$ & $1428(39.4)$ & $88(37.1)$ & $1569(39.0)$ \\
\hline Below bachelor & $113(68.1)$ & $2195(60.6)$ & $149(62.9)$ & $2457(61.0)$ \\
\hline \multicolumn{5}{|l|}{ Prenatal factors } \\
\hline Number of prenatal tests ${ }^{\star}$, mean $_{ \pm} \mathrm{SD}$ & $8.6 \pm 2.7$ & $9.2 \pm 2.4$ & $9.5 \pm 2.5$ & $9.2 \pm 2.4$ \\
\hline \multicolumn{5}{|l|}{ Maternal active smoking, $\mathrm{n}(\%)$} \\
\hline Yes & $0(0.0)$ & $5(0.1)$ & $0(0.0)$ & $5(0.1)$ \\
\hline No & $166(100)$ & 3618 (99.9) & $237(100)$ & 4021 (99.9) \\
\hline \multicolumn{5}{|l|}{ Maternal passive smoking, $\mathrm{n}(\%)$} \\
\hline Yes & $4(2.4)$ & $62(1.7)$ & $2(0.8)$ & $68(1.7)$ \\
\hline No & $162(97.6)$ & 3561 (98.3) & $235(99.2)$ & 3958 (98.3) \\
\hline \multicolumn{5}{|l|}{ Perinatal factors } \\
\hline \multicolumn{5}{|l|}{ Gender $^{\star}, \mathrm{n}(\%)$} \\
\hline Male & $85(51.2)$ & $2008(55.4)$ & $153(64.6)$ & $2246(55.8)$ \\
\hline Female & $81(48.8)$ & $1615(44.6)$ & $84(35.4)$ & $1780(44.2)$ \\
\hline Birth length* $(\mathrm{cm})$, mean \pm SD & $45.9 \pm 2.3$ & $50.1 \pm 1.5$ & $52.3 \pm 1.5$ & $50.1 \pm 1.8$ \\
\hline \multicolumn{5}{|l|}{ Asphyxia neonatorum, n (\%) } \\
\hline Yes & $0(0.0)$ & $7(0.2)$ & $0(0.0)$ & $7(0.2)$ \\
\hline No & $166(100.0)$ & $3616(99.8)$ & $237(100.0)$ & 4019 (99.8) \\
\hline \multicolumn{5}{|l|}{ Mode of delivery*, n (\%) } \\
\hline Natural & $57(34.3)$ & $898(24.8)$ & $23(9.7)$ & 978 (24.3) \\
\hline Caesarean & $109(65.7)$ & 2725 (75.2) & 214 (90.3) & 3048 (75.7) \\
\hline
\end{tabular}

${ }^{*} \mathrm{P}<0.05$.

LBW, low birth weight; NBW, normal birth weight.

adaptability (aOR 1.56, 95\% CI 1.06 to 2.31 ). LBW has no significant effects on neurodevelopmental delay in language and social behaviour. Macrosomia also has no significant effects on clinical diagnosis of neurodevelopmental delay in all domains.

\section{DISCUSSION}

This study examined the impact of BW on neurodevelopment of infants at age 1-6 months. The findings indicated that LBW is negatively associated with $\mathrm{DQ}$ in all neurological domains, and LBW increases the risk of 'neurodevelopmental delay' in gross motor, fine motor and adaptability. Macrosomia is also associated with $\mathrm{DQ}$ in all neurological domains; however, macrosomia has no significant impact on neurodevelopmental delay. The results of this study are consistent with previous studies conducted in developed countries. ${ }^{27} 28$

It is well documented that LBW results in a series of health problems both at the early stage of infancy and in adulthood. ${ }^{29}{ }^{30}$ However, the impact of LBW on neurodevelopment at an early age is less investigated ${ }^{31}$ and has drawn inconsistent conclusion with various limitations. Chan and colleagues ${ }^{32}$ reported that abnormal neural pathways and brain growth retardation may result in higher rates of delayed neurodevelopment in LBW, especially in terms of gross motor and fine motor performance. Other study that evaluated the impact of small for gestational age on behavioural development also suggested that small for gestational age is negatively associated with some attentional problems and aggressive behaviours in a 
Table 2 Associations between birth weight and DQ of infants by different neurodevelopmental domains

\begin{tabular}{|c|c|c|c|c|c|}
\hline & $\mathrm{DQ}($ mean $\pm S D)$ & $P_{1}$ value & B & $95 \% \mathrm{Cl}$ for $\mathrm{B}$ & $P_{2}$ value \\
\hline Gross motor DQ & $101.0 \pm 23.0$ & & & & \\
\hline NBW & $101.7 \pm 22.5$ & $<0.001$ & 0 & & \\
\hline Macrosomia & $104.4 \pm 21.9$ & & 0.49 & 0.36 to 0.63 & $<0.001$ \\
\hline Fine motor DQ & $107.2 \pm 29.9$ & & & & \\
\hline LBW & $86.8 \pm 27.6$ & & -6.57 & -6.76 to -6.39 & $<0.001$ \\
\hline Macrosomia & $109.7 \pm 28.3$ & & -2.73 & -2.87 to -2.59 & $<0.001$ \\
\hline Adaptability DQ & $85.5 \pm 22.3$ & & & & \\
\hline NBW & $85.9 \pm 22.2$ & $<0.001$ & 0 & & \\
\hline LBW & $76.6 \pm 23.5$ & & -4.87 & -5.05 to -4.68 & $<0.001$ \\
\hline NBW & $87.0 \pm 21.2$ & $<0.001$ & 0 & & \\
\hline LBW & $78.2 \pm 23.6$ & & -6.23 & -6.42 to -6.05 & $<0.001$ \\
\hline Macrosomia & $88.1 \pm 22.2$ & & 0.43 & 0.29 to 0.57 & $<0.001$ \\
\hline Social behaviour DQ & $87.8 \pm 22.3$ & & & & \\
\hline NBW & $88.1 \pm 22.0$ & $<0.001$ & 0 & & \\
\hline LBW & $77.6 \pm 25.0$ & & -6.82 & -7.0 to -6.64 & $<0.001$ \\
\hline Macrosomia & $90.3 \pm 22.5$ & & 1.10 & 0.96 to 1.24 & $<0.001$ \\
\hline
\end{tabular}

$\mathrm{P}_{1}$, one-way analysis of variance; $\mathrm{P}_{2}$, generalised linear model analysis, adjusted for prenatal factors (maternal active and passive smoking, and number of pregnancy tests), perinatal factors (gender of infants, delivery mode, asphyxia neonatorum and birth length) and maternal demographic factors (gestational weeks and education level of parents).

DQ, development quotient; LBW, low birth weight; NBW, normal birth weight.

school-age child. ${ }^{33}$ However, a study conducted by Ballot and colleagues, ${ }^{34}$ using the Bayley Scales of Infant Development, showed that LBW infants are more likely to have abnormal development outcomes in cognitive, motor and language subscales. The inconsistencies of these results may be related to the use of different indicators related to BW and different scales to assess neurodevelopment, timing of assessment and adjustment variables.

In the present study, we found that LBW primarily affects neurodevelopmental delay in gross motor, fine motor and adaptability during the early stage of infancy, which is different from a previous study, and may suggest LBW has different mechanisms for different types of neurodevelopmental delay. ${ }^{35}$ The sequence in which gross and fine motor skills are acquired does not vary during the early stage of child development, but the pace of acquisition differs from child to child. The results of the present study may also suggest that the onset of gross and fine motor development can be affected by LBW. Motor performance is mainly influenced by the maturation and plasticity of the brain motor system; thus, LBW influences motor skills mainly through its effect on motor system maturation and plasticity. ${ }^{36}$ Additionally, a poorer development of adaptability among LBW infants during the early stage of child development may also suggest there is neurodevelopmental damage associated with adaptability of the brain.

In this study, there was no significant difference between BW and neurodevelopmental delay in infants' language and social behaviours, which conflicts with a previous study. ${ }^{37}$ This inconsistency may be associated with the physiological age of neurodevelopment assessment. In the present study, we assessed neurodevelopment at age 1-6 months, in which the auditory function of infants, which plays a decisive role in language development, ${ }^{38}$ is not fully developed. In addition, the Chinese version of GDS rarely has test items for language and social behaviour for infants at age 1-6 months, which may also have certain impact on the test results. With an increase in age, there must be more items that can detect and accurately reflect infant language and social behaviour development.

Of note, in the present study, LBW does not have significant impact on language and social behaviour development among infants, which does not mean those aspects will not have an impact in the future if no effective interventions are taken. ${ }^{39}$ This is because neurodevelopment has specific processes, and these domains are interdependent, that is, each one influences and is influenced by the others. Motor behaviour favours children's experiences in acting and interacting, providing them with concrete 
Table 3 Association of birth weight with neurodevelopmental diagnosis by different neurodevelopmental domains ${ }^{\star}$

\begin{tabular}{|c|c|c|c|c|c|}
\hline & $\begin{array}{l}\text { Neurodevelopmental } \\
\text { delay, n (\%) }\end{array}$ & Wald $\chi^{2}$ & $P$ value & OR & $95 \% \mathrm{Cl}$ for OR \\
\hline \multicolumn{6}{|l|}{ Gross motor } \\
\hline LBW & $93(56.0)$ & 19.95 & $<0.001$ & 2.43 & 1.65 to 3.60 \\
\hline Macrosomia & $44(18.6)$ & 0.07 & 0.792 & 0.95 & 0.67 to 1.36 \\
\hline LBW & $93(56.0)$ & 4.01 & 0.045 & 1.49 & 1.01 to 2.19 \\
\hline Macrosomia & $54(22.8)$ & 0.04 & 0.839 & 1.03 & 0.74 to 1.44 \\
\hline \multicolumn{6}{|l|}{ Adaptability } \\
\hline NBW & 2038 (56.3) & Reference & & & \\
\hline NBW & 1929 (53.2) & Reference & & & \\
\hline LBW & $100(60.2)$ & 2.60 & 0.107 & 1.37 & 0.94 to 2.00 \\
\hline Macrosomia & $121(51.1)$ & 0.58 & 0.448 & 0.90 & 0.68 to 1.19 \\
\hline \multicolumn{6}{|l|}{ Social behaviour } \\
\hline NBW & 1844 (50.9) & Reference & & & \\
\hline LBW & 91 (54.8) & 1.25 & 0.264 & 1.24 & 0.85 to 1.79 \\
\hline Macrosomia & $113(47.7)$ & 0.91 & 0.339 & 0.87 & 0.66 to 1.15 \\
\hline
\end{tabular}

${ }^{*}$ Adjusted for prenatal factors (maternal active and passive smoking, and number of pregnancy tests), perinatal factors (gender of infants, delivery mode, asphyxia neonatorum and birth length) and maternal demographic factors (gestational weeks and education level of parents). LBW, low birth weight; NBW, normal birth weight.

opportunities that favour the development in perceptual, cognitive, linguistic, adaptive and social areas. Therefore, motor neurodevelopmental delay may reflex on all areas of child development. ${ }^{40}$ However, from another perspective, targeted inventions in the early stages of neurodevelopmental delay will achieve the greatest benefits. ${ }^{41}$

The present study has not found a significant correlation between macrosomia and neurological diagnosis, echoing previous studies. Some previous studies have suggested that the adaptability of a 6-month-old with macrosomia lags behind that of an NBW infant, and this difference still exists at 12 months. ${ }^{42}$ It should be mentioned that the mechanisms and impact of LBW and macrosomia on neurodevelopment may be different. Therefore, the impact and mechanism of macrosomia on neurodevelopment need to be validated and examined in future studies.

\section{Strengths and limitations}

The main strength of this study was the use of a perspective cohort which provided detailed data collected from pregnancy through 6-month-old newborns, thus allowing for multiple risk factors analysis of infants' neurodevelopment. Additionally, developing countries have specific socioeconomic and cultural factors, as shown by this study's sample, such as lower obesity rate, higher caesarean section rate and lower smoking rate, all of which allow for adjustment for a wide range of risk factors that may be associated with infants' neurodevelopment. Thus, the results of this study are of great value to policy makers to guide and implement intervention programmes aimed at improving infants' neurodevelopment in developing countries.

There are some limitations to this study. First, we do not have data on neurodevelopment after 6 months of age, which are required to further observe the effects of BW on long-term neurodevelopment. Second, there are only few items that assess neurodevelopment of infants aged 1-6 months in the revised GDS, and this led to less sensitive assessment results. It is unwise to reflect on infants' developmental pattern with only one assessment result ${ }^{43}$; however, the revised GDS is widely used for neurodevelopmental assessment and diagnosis in China. Additionally, the associations of BW with $\mathrm{DQ}$ are not in line with the associations of BW with clinical diagnosis of neurodevelopmental delay, which may suggest the norm of GDS at early stage of infancy needs revison. Third, the revised GDS is not commonly used in Western countries, making the comparison of the association of BW with 
neurodevelopment among different studies difficult. Therefore, further studies are warranted to determine whether and to what extent BW has an impact on the neurodevelopment of a child.

\section{CONCLUSION}

In conclusion, by studying the relationship between neurodevelopmental status and BW among infants aged 1-6 months in the WHBC, we could conclude that both LBW and macrosomia are associated with DQ in infants, and LBW increases the risk of a diagnosis of 'neurodevelopment delay'. The risks involved gross and fine motors and adaptability in babies. Further studies are warranted to determine whether, to what extent and how BW affects the neurodevelopment of a child.

Acknowledgements We would like to acknowledge all participating families for their continuing participation in the study. We would also like to thank our colleagues and the study staff at Women and Children's Hospital of Wuhan for their commitment to data collection.

Contributors TJ, YY and MMG conceived the study idea. MZ and YRC performed the literature search. ZC, MZ and BZ were involved in data collection. MZ wrote the first draft of the manuscript. MMG and TJ critically revised the manuscript. All authors approved the final version of the manuscript. TJ had full access to all of the data (including statistical reports and tables) in the study, and takes responsibility for the integrity of the data and the accuracy of the data analysis.

Funding This study was supported by the National Natural Science Foundation of China (Grant No 81773457) and was partially supported by the National Natural Science Foundation of Guangdong Province (Grant No 2015A030313455). The funders had no role in study design, data collection and analysis, decision to publish, or preparation of the manuscript.

Competing interests None declared.

Patient consent for publication Not required.

Ethics approval The WHBC study was approved by the Institutional Review Board of Women and Children's Hospital of Wuhan (no 2010009), and written informed consent was obtained from participants' parents before recruitment. The present study was approved by the Review Board of Guangzhou Medical College (no [2015]17).

\section{Provenance and peer review Not commissioned; externally peer reviewed.}

Data availability statement Data are available upon reasonable request. All of the de-identified individual participant data used in this study can be shared with investigators by contacting the corresponding author. Other data of the WHBC study are available (including data dictionaries) for investigators whose proposed use of the data has been approved by an independent review committee identified for this purpose by contacting the WHBC study team.

Open access This is an open access article distributed in accordance with the Creative Commons Attribution Non Commercial (CC BY-NC 4.0) license, which permits others to distribute, remix, adapt, build upon this work non-commercially, and license their derivative works on different terms, provided the original work is properly cited, appropriate credit is given, any changes made indicated, and the use is non-commercial. See: http://creativecommons.org/licenses/by-nc/4.0/.

ORCID iD

Man Zhang http://orcid.org/0000-0002-0568-8444

\section{REFERENCES}

1 Abdallah Y, Namiiro F, Nankunda J, et al. Mortality among very low birth weight infants after hospital discharge in a low resource setting. BMC Pediatr 2018;18:239-6.

2 Fanaroff AA, Stoll BJ, Wright LL, et al. Trends in neonatal morbidity and mortality for very low birthweight infants. Am J Obstet Gynecol 2007;196:147.e1-8.
3 UNICEF. Low birth weight: percentage of infants weighing less than 2500grams at birth. Available: http://data.unicef.org/nutrition/lowbirthweight.html

4 Lawn JE, Blencowe H, Oza S, et al. Every newborn: progress, priorities, and potential beyond survival. Lancet 2014;384:189-205.

5 National Bureau of Statistics. Statistical report on the implementation of the 2013 China children's development program (2011-2020). Chin Information News, 2015.

6 Wang LZ, Cao J, Liu GY, et al. An investigation of physical development of 5027 neonates in Urumqi, China. CJC Pediatrics 2018;20:994-1001.

7 Cutland CL, Lackritz EM, Mallett-Moore T, et al. Low birth weight: Case definition \& guidelines for data collection, analysis, and presentation of maternal immunization safety data. Vaccine 2017;35:6492-500.

8 Magdaleno R, Pereira BG, Chaim EA, et al. Pregnancy after bariatric surgery: a current view of maternal, obstetrical and perinatal challenges. Arch Gynecol Obstet 2012;285:559-66.

9 Paltiel O, Lemeshow S, Phillips GS, et al. The association between birth order and birth weight. Pooled results from the International Childhood Cancer Cohort Consortium(14C). Int J Cancer 2019;144:26-33.

10 Tian J-Y, Cheng Q, Song X-M, et al. Birth weight and risk of type 2 diabetes, abdominal obesity and hypertension among Chinese adults. Eur J Endocrinol 2006;155:601-7.

11 Kiy AM, Rugolo LMSS, De Luca AKC, et al. Growth of preterm low birth weight infants until 24 months corrected age: effect of maternal hypertension. J Pediatr 2015;91:256-62.

12 Rijken M, Wit JM, Le Cessie S, et al. The effect of perinatal risk factors on growth in very preterm infants at 2 years of age: The Leiden Follow-Up Project on Prematurity. Early Hum Dev 2007;83:527-34.

13 Ficks CA, Lahey BB, Waldman ID. Does low birth weight share common genetic or environmental risk with childhood disruptive disorders? J Abnorm Psychol 2013;122:842-53.

14 Cejas G, Gómez Y, Roca MdelC, et al. Neurodevelopment of very low birth weight infants in the first two years of life in a havana tertiary care hospital. MEDICC Rev 2015;17:14-17.

15 Ballot DE, Potterton J, Chirwa T, et al. Developmental outcome of very low birth weight infants in a developing country. BMC Pediatr 2012;12:11-10.

16 Zeng Y, Hesketh T. The effects of China's universal two-child policy. Lancet 2016;388:1930-8.

17 Meyers JM, Bann CM, Stoll BJ, et al. Neurodevelopmental outcomes in postnatal growth-restricted preterm infants with postnatal headsparing. J Perinatol 2016;36:1116-21.

18 Yang J, Huo W, Zhang B, et al. Maternal urinary cadmium concentrations in relation to preterm birth in the healthy baby cohort study in China. Environ Int 2016;94:300-6.

19 Hsu C-T, Chen C-H, Lin M-C, et al. Correction: post-discharge body weight and neurodevelopmental outcomes among very low birth weight infants in Taiwan: a nationwide cohort study. PLoS One 2019;14:e0211526.

20 Gesell A, Amatruda C. Developmental diagnosis: normal and abnormal child development, clinical methods and pediatric applications. New York: Hoeber, 1941.

21 Hou S, Yuan L, Jin P, et al. A clinical study of the effects of lead poisoning on the intelligence and neurobehavioral abilities of children. Theor Biol Med Model 2013;10:13-19.

22 Ji T, Yang Z, Liu Q, et al. Vagus nerve stimulation for pediatric patients with intractable epilepsy between 3 and 6 years of age: study protocol for a double-blind, randomized control trial. Trials 2019;20:44-10.

23 Zhang $\mathrm{H}$, Zhang B, Jia F, et al. The effects of motor and intellectual functions on the effectiveness of comprehensive rehabilitation in young children with cerebral palsy. $J$ Int Med Res 2015;43:125-38.

24 Guo M, Li L, Zhang Q, et al. Vitamin and mineral status of children with autism spectrum disorder in Hainan Province of China: associations with symptoms. Nutr Neurosci 2018;89:1-8.

25 Tavasoli A, Aliabadi F, Eftekhari R. Motor developmental status of moderately low birth weight preterm infants. Iran $J$ Pediatr 2014;24:581-6.

26 Stoinska B, Gadzinowski J. Neurological and developmental disabilities in ELBW and VLBW: follow-up at 2 years of age. $J$ Perinatol 2010;31:42-137.

27 Lund LK, Vik T, Lydersen S, et al. Mental health, quality of life and social relations in young adults born with low birth weight. Health Qual Life Outcomes 2012;10:146-10.

28 Lopes AAT, Tani G, Katzmarzyk PT, et al. Association between birth weight and neuromotor performance: a twin study. Scand J Med Sci Sports 2014;24:e140-7. 
29 Hack M, Schluchter M, Andreias L, et al. Change in prevalence of chronic conditions between childhood and adolescence among extremely low-birth-weight children. JAMA 2011;306:394-401.

$30 \mathrm{JQ}$ W, Rong F, YY L, et al. Relationship between high birth weight and overweight, obesity, metabolic anomalies in childhood. Chin J Sch Health 2012;33:304-6.

31 Liu GH, Qian GF, Ou P, et al. Effect of transitional care on the growth and development in very low and extremely low birth weight premature infants. Chin J Nurs 2015;50:697-703.

32 Chan SHT, Johnson MJ, Leaf AA, et al. Nutrition and neurodevelopmental outcomes in preterm infants: a systematic review. Acta Paediatr 2016;105:587-99.

33 Takeuchi A, Yorifuji T, Takahashi K, et al. Behavioral outcomes of school-aged full-term small-for-gestational-age infants: a nationwide Japanese population-based study. Brain Dev 2017;39:101-6.

34 Ballot DE, Ramdin T, Rakotsoane D, et al. Assessment of developmental outcome in very low birth weight infants in southern Africa using the Bayley scales of infant development (III). BMJ Paediatrics Open 2017;1:e000091-7.

35 Ribeiro CD, Pachelli MR, Amaral NC, et al. Development skills of children born premature with low and low birth weight. Codas 2017;29:e20160058.

36 van Noort-van der Spek IL, Franken M-CJP, Weisglas-Kuperus N. Language functions in preterm-born children: a systematic review and meta-analysis. Pediatrics 2012;129:745-54.
37 Wang Y, Zhang SY, Yu H, et al. Control study on the physical and mental development of macrosomia and term infants appropriate for gestational within two years old. Progress in Modern Biomedicine 2014:14:4541-4.

$38 \mathrm{Li} \mathrm{J}, \mathrm{Bo} \mathrm{T}$, Chen TQ, et al. Neurobehavioral development in preterm infants: a retrospective study of 181 cases. Chin J Contemp Pediatr 2014;16:696-700.

39 Mürner-Lavanchy IM, Doyle LW, Schmidt B, et al. Neurobehavioral outcomes 11 years after neonatal caffeine therapy for apnea of prematurity. Pediatrics 2018;141:e2017047.

40 Kutschera J, Tomaselli J, Maurer U, et al. Minor neurological dysfunction, cognitive development, and somatic development at the age of 3 to 7 years after dexamethasone treatment in very-low birthweight infants. Early Hum Dev 2005;81:281-7.

41 Pramana IA, Neumann RP. Follow up care of the preterm infant. Ther Umsch 2013;70:648-52.

42 Wang D, Zhu L, Zhang S, et al. Predictive macrosomia birthweight thresholds for adverse maternal and neonatal outcomes. J Matern Fetal Neonatal Med 2016;29:3745-50.

43 Guo JH, Duan XH, XS H, et al. The investigation and analysis of macrosomia in physical and neurological and psychiatric development. CJCHC 2001;9:58-9. 